This item was submitted to Loughborough's Research Repository by the author.

Items in Figshare are protected by copyright, with all rights reserved, unless otherwise indicated.

\title{
Applying close range digital photogrammetry in soil erosion studies
}

PLEASE CITE THE PUBLISHED VERSION

http://dx.doi.org/10.1111/j.1477-9730.2010.00584.x

\section{PUBLISHER}

(c) The Authors. The Photogrammetric Record () The Remote Sensing and Photogrammetry Society and Blackwell Publishing Ltd.

\section{VERSION}

AM (Accepted Manuscript)

LICENCE

CC BY-NC-ND 4.0

\section{REPOSITORY RECORD}

Heng, B.C. Peter, Jim H. Chandler, and Alona Armstrong. 2019. "Applying Close Range Digital Photogrammetry in Soil Erosion Studies". figshare. https://hdl.handle.net/2134/8999. 
This item was submitted to Loughborough's Institutional Repository (https://dspace.lboro.ac.uk/) by the author and is made available under the following Creative Commons Licence conditions.

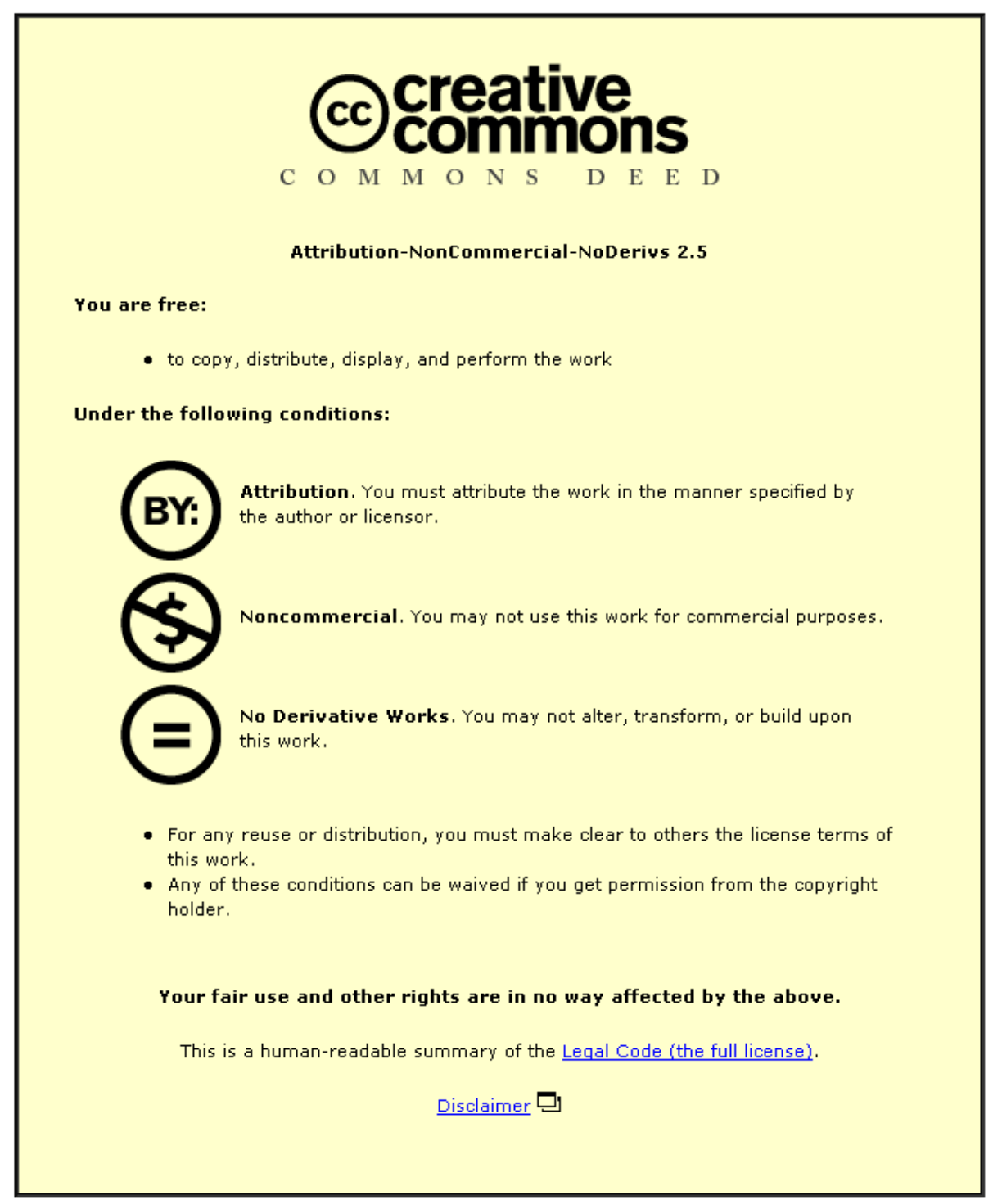

For the full text of this licence, please go to: http://creativecommons.org/licenses/by-nc-nd/2.5/ 


\title{
APPLYING CLOSE RANGE DIGITAL PHOTOGRAMMETRY IN SOIL EROSION STUDIES
}

\author{
By B. C. PETER HENG (b.c.p.heng@lboro.ac.uk), \\ JIM H. CHANDLER (j.h.chandler@lboro.ac.uk), \\ Department of Civil and Building Engineering, Loughborough University, \\ Loughborough, Leicestershire LE11 3TU, UK \\ and ALONA ARMSTRONG (alona.armstrong@lancaster.ac.uk) \\ Lancaster Environment Centre, Lancaster University, Lancaster, LA1 4YQ, UK
}

\begin{abstract}
Soil erosion due to rainfall and overland flow is a significant environmental problem. Studying the phenomenon requires accurate high-resolution measurements of soil surface topography and morphology. Close range digital photogrammetry with an oblique convergent configuration is proposed in this paper as a useful technique for such measurements, in the context of a flume-scale experimental study. The precision of the technique is assessed by comparing triangulation solutions and the resulting DEMs with varying tie point distributions and control point measurements, as well as by comparing DEMs extracted from different images of the same surface. Independent measurements were acquired using a terrestrial laser scanner for comparison with a photogrammetry-derived DEM. The results point to the need for a stronger geometric configuration to improve precision. They also suggest that the camera lens models were not fully adequate for the large object depths in this study. Nevertheless, the photogrammetric output can provide useful topographical information for soil erosion studies, provided limitations of the technique are duly considered.
\end{abstract}

KEYWORDS: Close range, digital photogrammetry, soil surface measurement, morphology, oblique imagery, precision, dome effects

\section{INTRODUCTION}

SoIL erosion is a significant environmental problem in many parts of the world, with negative impacts on agricultural productivity, water quality, and 
aquatic ecology. Surface runoff generated by high-intensity rainfall is particularly erosive and has the capacity to transport eroded sediment quickly and in large quantities into surface waters (Toy et al., 2002). As such, predicting the magnitude and direction of surface runoff is essential for soil erosion modelling. Soil surface microtopography is significant in this respect because overland flow is typically very shallow. This was highlighted by Takken et al. (2001) in a study comparing the outputs of a soil erosion model with and without accounting for tillage patterns on agricultural fields. The authors concluded that accurate and detailed digital elevation models (DEMs) are necessary for accurate soil erosion modelling. In addition, obtaining accurate descriptions of soil surface microtopography is vital to quantify changes to the soil surface (typically on the sub-centimetre scale) due to erosion processes.

In this paper, we investigate the use of close range digital photogrammetry (CRDP) for soil surface measurements in support of experimental and modelling studies into soil erosion on agricultural slopes and the consequent transport of sediments and nutrients by overland flow. For reasons discussed in the next section, we adopted an oblique and convergent photogrammetric configuration in our study, making use of high-resolution consumer-grade digital cameras for image acquisition. The following sections describe the methodology and present results of error analyses, including checking against independent measurements obtained by laser scanning. Finally, we discuss the uses and limitations of the proposed photogrammetric configuration in soil erosion investigations.

\section{SOIL SURFACE MEASUREMENT - PREVIOUS WORK}

Various techniques have been proposed to measure soil surface microtopography; their relative strengths and weaknesses were discussed in recent comparative studies (Jester and Klik, 2005; Aguilar et al., 2009). Project requirements and constraints have to be considered in selecting a suitable technique. Our project required sufficiently accurate and precise DEMs of a relatively large soil surface $(3.9 \mathrm{~m}$ by $1.4 \mathrm{~m})$ for overland flow and sediment transport modelling, and to quantify changes to soil surface elevation due to erosion processes. Fifteen experimental runs were to be carried out, with data acquisition (for surface modelling) before, during, and after each run. As such, data acquisition (after the initial setup) had to be quick and easy. In view of these requirements, close range photogrammetry appeared to be most suitable as well as cost effective.

An early application of photogrammetry in soil surface measurement was presented by Martin (1980), who used the technique to quantify surface roughness within a $0.36 \mathrm{~m}^{2}$ area. Helming et al. (1993) studied a smaller area at high resolution ( $2 \mathrm{~mm}$ grid distance, $0.2 \mathrm{~m}$ height resolution), relating microrelief measurements to surface runoff under simulated rainfall. Merel and Farres (1998) used analytical photogrammetry on $1 \mathrm{~m}^{2}$ plots in the field to determine surface elevation changes due to erosion events.

More recently, Lascelles et al. (2002) used digital photogrammetry with a non-metric 1.5-megapixel digital camera to study the evolution of a $4 \times 1.75 \mathrm{~m}$ soil surface under simulated rainfall. In order to cover the relatively large area in 
one image (at each camera position), they mounted the camera $4 \mathrm{~m}$ above the soil surface. The ground sample distance (GSD) works out to be approximately $3 \mathrm{~mm}$. Since DEM cell size is typically five to ten times the GSD, it is likely that centimetre resolutions were obtained using this setup. Rieke-Zapp and Nearing (2005) obtained better DEM resolutions by positioning their 6-megapixel camera $1.9 \mathrm{~m}$ above the soil surface and acquiring 16 images per block to cover the $16 \mathrm{~m}^{2}$ area.

Zribi et al. (2000), Taconet and Ciarletti (2007), and Blaes and Defourny (2008) demonstrated the utility of close range photogrammetry for the characterisation of soil surface roughness, an important variable in remote sensing as well as in runoff and erosion processes. Photogrammetry-derived output was shown to correlate well with pin meter measurements of soil surface microtopography (Abd Elbasit et al., 2009).

Normal photography (that is, imagery where the camera axis is normal to the soil surface) was used in all the above-mentioned studies. This restricted the area of coverage per stereo model to $1 \mathrm{~m}^{2}$ or less, given the requirement for subcentimetre precision in $Z$. For larger study areas, a larger block of images had to be acquired, with a corresponding increase in image acquisition time. Rieke-Zapp and Nearing (2005) reported image acquisition times of 10 min per block. This reduces the appeal of using photogrammetry over other techniques such as laser scanning, given that one of its strengths is the possibility of instantaneous data capture. Furthermore, a larger number of images would mean longer processing times. On the other hand, one can take advantage of continuing advancements in sensor technology (larger sensors with more pixels) to cover the same study area with fewer images.

Alternatively, an oblique configuration may be adopted so that each image covers a larger soil surface area. This is particularly advantageous for a rectangular flume or plot, which is common in soil erosion experiments. It also allows greater flexibility in the positioning of cameras: they do not have to be positioned over the soil surface being monitored. If two or more cameras are used in a convergent configuration, such that each image covers the whole soil surface, the cameras can be fixed in place before and during a rainfall event. This further reduces the image acquisition time and may also improve camera stability. The oblique and convergent photogrammetric configuration adopted in our study is described in the next section, which also details the photogrammetric processing and the laser scanning used to acquire independent measurements.

\section{METHODOLOGY}

Setup

Two ten-megapixel Nikon D80 digital SLR cameras, each equipped with an 18-70 mm variable zoom Nikkor AF-S DX lens, were used in this study, although only one camera was available for some of the experimental runs (details in the next subsection). The cameras were mounted on articulated arms and positioned as shown in Fig. 1. They were oriented such that their axes converged at a point 
roughly below the mid-point of the soil surface, on the basis that convergent imagery reduces the spurious dome effects associated with small errors in the lens distortion models (Wackrow and Chandler, 2008). The base distance $(B)$ was approximately $0.6 \mathrm{~m}$, giving an average base-to-'height' ratio of $1: 5.3$, and an angle of convergence of approximately 10 degrees. This configuration allowed for complete coverage of the soil surface from fixed camera positions, thus minimising image acquisition and processing times. It also eased the task of the experimentalist, who had not previously received training in photogrammetry.

With oblique imagery, consideration should be given to optimising the depth of field so that image features vital for DEM extraction are not out of focus. We set the camera aperture at $\mathrm{f} / 8$ and the lens at $24 \mathrm{~mm}$ zoom with a hyperfocal distance setting providing a depth of field between $1.5 \mathrm{~m}$ and infinity. The shutter speeds were allowed to vary for optimum image exposure under the combined natural and normal laboratory lighting. This resulted in exposure times ranging from $1 / 30$ to $1 / 6 \mathrm{~s}$. In a few instances, the relatively long exposure times produced 'camera shake' effects, which did adversely affect the DEMs generated. To overcome this, redundant replicate images of each scene were acquired, which was easily accomplished given the setup. It also allowed us to generate multiple DEMs of the same surface for subsequent error analysis (see Results). The camera settings are summarised in Table I.

TABLE I. Camera settings.

\begin{tabular}{cc}
\hline Parameter & Value \\
\hline Camera sensor size & $23.6 \times 15.8 \mathrm{~mm}$ \\
Pixel size & $6.095 \times 6.095$ microns \\
Image resolution & 10 million pixels \\
& $(3872 \times 2592)$ \\
Aperture & $\mathrm{f} / 8$ \\
Depth of field & $1.5 \mathrm{~m}$ to $\infty$ \\
ISO rating & 800 \\
\hline
\end{tabular}

Ten targets glued onto 45 degree wooden blocks were attached to the sides of the flume, with two additional targets at the top two corners (Fig. 2). These were oriented in the direction of the cameras and provided a fixed set of ground control points (GCPs) for repeated photogrammetric surveys. We could not place GCPs on the soil surface itself as they would have disturbed the erosion processes we were trying to study. The GCPs were surveyed from two positions using a reflectorless total station based on an arbitrary coordinate system with the $Y$ axis roughly parallel to the length of the flume and the $Z$ axis in the vertical direction. The two sets of measurements were then combined in a least squares "variation of coordinates' program to derive the best coordinate estimates. An a posteriori analysis suggests that the control points were precise to within $1 \mathrm{~mm}$. 


\section{Experimental Programme}

The experimental soil erosion study is detailed in Armstrong et al. (in review) but is summarised here for completeness. A silt loam (4.6\% clay, $49.9 \%$ silt and $45.5 \%$ sand) was used in the study, under five different experimental scenarios (designated $\mathrm{A}$ to $\mathrm{E}$ ), each involving triplicate runs (designated R1, R2 and R3 respectively). In the first three scenarios, we quantified the erosion response under constant rainfall $(47 \mathrm{~mm} / \mathrm{h})$ at $3 \%, 6 \%$ and $9 \%$ slopes (A, B and $\mathrm{C}$ respectively). Scenarios D and E both involved a steep-gentle two-gradient slope (9\% and 3\% on the upper and lower reaches respectively), the former under constant rainfall (47 $\mathrm{mm} / \mathrm{h}$ ) and the latter under run-on (with varying inflow rates) events. Rainfall was simulated by pumping de-ionised water through four Fulljet 1/2 HH 40WSQ nozzles. Rainfall intensity was measured using rain gauges at regularly spaced points on the soil surface between experimental runs, giving us information on the spatial and temporal variations in rainfall. In all cases, the soil was placed and compacted to a bulk density of $1.3 \mathrm{~kg} / \mathrm{m}^{3}$, and the surface prepared as a seed bed.

Stereo-photographs of the soil surface were captured simultaneously using the two cameras before, after and, for some runs, during the experimental runs for Scenarios A, B and C. For Scenarios D and E, only one camera was available, so the camera had to be moved to capture images from both camera positions.

\section{Digital Photogrammetry}

The Leica Photogrammetry Suite (LPS) 9.0 (Leica Geosystems, 2005) facilitated data processing and extraction from the acquired imagery. Each block contained two images, each frame associated with a different lens distortion model (representing the two cameras used). GCP object coordinates were imported into the block and image coordinates measured manually. This was followed by an initial triangulation to estimate camera exterior orientations.

It is, of course, necessary to consider aspects of interior orientation when undertaking any photogrammetric project. The flume setup in this study did not provide a strong geometry for self calibration. As such, a dual calibration approach was adopted. The lens models (with lens distortion coefficients $k_{1}$ and $k_{2}$ ) were established based on separate convergent imagery acquired of a 3D test field using an external bundle adjustment program and a well-established methodology (Chandler et al. 2005). In view of the recognised instability of consumer-grade digital cameras (Shortis et al., 1998a; Chandler et al., 2005; Rieke-Zapp et al., 2009), the primary parameters ( $\left.c, x_{p}, y_{p}\right)$ were established using the imagery captured for final DEM generation, that is, using an in situ self calibration approach. Thus, in the final triangulation with LPS, we allowed for (unweighted) corrections to the principal distances and principal point offsets for each image pair acquired. We believe that this dual strategy is an effective way of dealing with camera instability, whilst reducing the chance of deriving unrealistic and hence inaccurate parameter sets.

To improve the reliability of the in situ self calibration, a large number of tie points $(>150)$ on the soil surface was generated, using the default strategy for tie point generation (Table II) and improving the coverage by specifying a $10 \times 10$ pattern distribution. The algorithm was accurate in all but a few instances (which 
required manual rectification by the operator). However, since the soil aggregates were mostly rounded without any clearly defined edges or points, the measurement of the tie points could conceivably be affected by the direction of illumination and the orientation of the cameras (Fig. 3). For this reason, and given that the GCPs were measured manually, we assigned a relatively low precision ( 0.5 pixels, equivalent to 3.05 microns) to the image points for triangulation. The stochastic constraints assigned to the triangulation parameters are summarised in Table III.

TABLE II. Parameters for automatic tie point generation.

\begin{tabular}{cc}
\hline Parameter & Value \\
\hline Search size & $21 \times 21$ pixels \\
Correlation size & $7 \times 7$ pixels \\
Least square size & $21 \times 21$ pixels \\
Coefficient limit & 0.8 \\
\hline
\end{tabular}

TABLE III. Stochastic constraints assigned to triangulation parameters.

\begin{tabular}{cc}
\hline Parameter & Value \\
\hline Convergence value (ground coordinates) & $1 \mathrm{~mm}$ \\
Image point standard deviations in $\mathrm{x}$ and $\mathrm{y}$ & 0.5 pixels \\
GCP standard deviations in X, Y and Z & $1 \mathrm{~mm}$ \\
Interior orientation parameters & Different unweighted corrections \\
\hline
\end{tabular}

\section{DEM Extraction}

A DEM of the overlapping region (and derivatives such as contour maps) can be extracted from the imagery once the interior and exterior orientations have been established. The control and tie points were used as seed data to improve the accuracy of the DEMs created by the standard LPS automatic terrain extraction algorithm. DEM resolution was limited by the ground resolution at the point (within the area of interest) furthest away from the cameras. We set DEM resolution at $10 \times 10 \mathrm{~mm}$, approximately eight times the GSD near the top boundary of the flume. This of course limited subsequent analyses to topographical features on the scale of large aggregates on the soil surface.

The quality of a DEM depends very much on the number and distribution of matching feature points (also known as mass points) identified by the image matching algorithm. Thus, as a preliminary check, we generated a '3D Shape' file (which shows graphically the positions of the mass points) for each image block before generating a raster representation of the DEM and other derivatives such as contour maps. To improve the distribution of mass points in our study (see below), we enlarged the search window perpendicular to the epipolar line from 3 (the default setting) to 9 pixels. No smoothing was applied as we wanted to retain all 
surface elevation detail and better understand what had been measured. The DEM extraction strategy is summarised in Table IV.

\begin{tabular}{cc} 
TABLE IV. DEM extraction strategy. \\
\hline Parameter & Value \\
\hline Search size & $21 \times 9$ pixels \\
Correlation size & $7 \times 7$ pixels \\
Correlation limit & 0.8 \\
Smoothing & None \\
\hline
\end{tabular}

\section{Terrestrial Laser Scanning}

A terrestrial laser scanner-Leica's ScanStation 2-was used to independently assess the accuracy of the photogrammetry. The ScanStation 2 is a timed pulse scanner with a maximum scanning rate of 50,000 points per second, and a single measurement accuracy of $4 \mathrm{~mm}$ with respect to distance and $6 \mathrm{~mm}$ with respect to position (Leica Geosystems, 2007). Notwithstanding its scanning speed, the whole data acquisition process (including physical setup, system initialisation, target acquisition, and scanning the soil surface at sub-centimetre resolution) took more than an hour, partly due to the fact that the scanning was carried out from two positions, in order to cover the whole area (Fig. 1). Due to time constraints, we carried out the laser scanning for just one of the experimental runs (the first of the Scenario D runs, before the erosion event).

Data processing involved using Leica Geosystem's Cyclone 6.0 (Leica Geosystems, 2008) to merge the point clouds into one dataset (Fig. 4), using the original control targets attached to the sides of the flume as constraints. This was again not trivial, for although the software could in theory pick out the targets automatically, the accuracy of the selection was poor, hence requiring some manual intervention on the part of the operator. A DEM was generated based on the merged point cloud (transformed into the coordinate system used for the photogrammetry) for eventual comparison with the photogrammetry-derived DEM.

\section{RESULTS}

A total of 54 pairs of images were processed using LPS: four pairs per experimental run (two before and two after the event) for Scenarios A, B, C and E, and two pairs per run (one before and one after the event) for Scenario D.

The a posteriori image point RMSEs were large: 4.88 microns, or 0.8 pixels, on average. In limited trials, we found that the RMSEs can be four times larger if interior orientation parameters were held fixed during triangulation. This is not surprising, given that the original parameters were obtained more than a year before this work and with a different test field.

An examination of the pattern and distribution of the residuals (obtained with self calibration) reveals clear systematic errors in the near field as well as the 
distant (Fig. 5, left). Perhaps unsurprisingly, the residuals were reduced if only a subset of the control and tie points (within the top half of the flume) were used in the triangulation (Fig. 5, right). At the same time, a significantly different set of solutions for interior and exterior orientation were obtained (Table V). In particular, the principal distances obtained using the point subset were smaller than those obtained using all of the points. This is consistent with the equation (Mikhail et al., 2001)

$$
\frac{1}{c}+\frac{1}{s}=\frac{1}{f}
$$

where $s$ is the object distance and $f$ the focal length, in that the point subset has a mean object distance larger than that of the full set (although any principal distance estimate can only be approximate due to its coupling with exterior orientation). This effect points to the influence of object depth on the accuracy of the photogrammetry (see discussion below).

TABLE V. Solutions for exterior and interior orientation for Scenario B, R1 using all available control and tie points or only a subset.

\begin{tabular}{cccccccccccc}
\hline $\begin{array}{c}\text { Control } \\
\begin{array}{c}\text { and tie } \\
\text { points } \\
\text { used }\end{array}\end{array}$ & Image & & \multicolumn{4}{c}{ Exterior orientation } & \multicolumn{5}{c}{ Interior orientation } \\
\cline { 3 - 11 } & 1 & 100.059 & 100.280 & 12.958 & 46.867 & -5.896 & 1.666 & 22.752 & 0.165 & 1.081 \\
All & 2 & 100.653 & 100.455 & 12.906 & 42.345 & 7.485 & 4.045 & 21.766 & -0.119 & -0.045 \\
\hline $\begin{array}{l}\text { Subset } \\
\begin{array}{c}\text { upper } \\
\text { slope })\end{array}\end{array}$ & 1 & 100.077 & 100.431 & 12.814 & 43.415 & -5.493 & 1.364 & 21.010 & -0.046 & -0.187 \\
\hline
\end{tabular}

Given the large image residuals, the default DEM extraction strategy in LPS (with a search window of 21 pixels along the epipolar line and 3 pixels across) proved to be inappropriate, resulting a patchy distribution of mass points and a correspondingly poor DEM (Fig. 6, left). Increasing the size of the search window perpendicular to the epipolar line from 3 to 9 pixels improved both mass point distribution and the corresponding DEM (Fig. 6, right). We note that, due to the oblique configuration, the size of the search window in object space changes according to its position. This is arguably a drawback of the configuration adopted in this study. Nevertheless, the improvements resulting from a larger search window show that this potential pitfall can be overcome. Alternatively, one could use different DEM extraction strategies for the top and bottom halves of the flume.

Some clearly spurious mass points can be observed near the top of the flume (Fig. 6), which can be attributed to the poor image resolution of that region and the occlusion of surface features by soil clods. We focus on the central region (offset by $0.1 \mathrm{~m}$ from the boundaries) in the following analyses. 


\section{Comparing DEMs of the Same Surface}

A comparison of DEMs of the same surface extracted from different images is one way of assessing the precision and, to some extent, the accuracy of the technique. Different image pairs would produce differing triangulation solutions (and hence DEMs) due to random errors in GCP measurement and differences in the distribution of tie points (as demonstrated above), both of which are dependent on image quality.

The mean difference and standard deviation of difference between two DEMs of the same surface for 24 soil surfaces (before and after each run for Scenarios A, B, C and E) are shown in Fig. 7. The error values largely reflect uncertainties in the solutions for interior and exterior orientation due to 'random' tie point distributions and errors in GCP measurement. The theoretical precision in $Z$ is (Kraus, 1993)

$$
\sigma_{Z}=m \frac{H}{B} \sigma_{0}
$$

where $m$ is the scale number, $H$ the object distance and $\sigma_{0}$ the precision of point measurements. Using mean values $m=150, H=3.2 \mathrm{~m}$ and $B=0.6 \mathrm{~m}$, and assuming $\sigma_{0}=3.0$ microns, we get $\sigma_{Z}=2.4 \mathrm{~mm}$, which agrees with the standard deviations in Fig. 7.

To isolate and examine the effect of random human error on the photogrammetry, we processed two blocks identical in every respect (same image pair, same tie points, etc.) except in the measurement of GCPs, which was done independently. The RMSE of all GCP measurements in the imagery was approximately 0.25 pixels or 1.5 microns, with consequent differences in the solutions for exterior and interior orientations. The triangulated tie point coordinates differed by $0 \cdot 12,0 \cdot 13$ and $0.07 \mathrm{~mm}$ on average-with corresponding standard deviations of $0.11,0.42$ and $0.29 \mathrm{~mm}-$ in $X, Y$ and $Z$ respectively. The resulting DEMs were displaced relative to each other, as is evident from Fig. 8. The mean difference between the DEMs was $0.22 \mathrm{~mm}$, with a standard deviation of $1.59 \mathrm{~mm}$. Fig. 8 suggests that the relative displacement was of the order of 10 $\mathrm{mm}$, but this is an artefact of interpolating from the nearest neighbouring value in DEMs with a $10 \mathrm{~mm}$ cell size. With a bilinear interpolation scheme, the relative displacement becomes imperceptible, and the mean difference between the DEMs drops to $0.07 \mathrm{~mm}$, with a standard deviation of $1.06 \mathrm{~mm}$.

For the before-run soil surface of R2 under Scenario B (B/R2/bf), a clearly visible dome effect in the difference DEM (Fig. 9) contributed to the unusually large mean error and standard deviation. Fig. 10 shows elevation values and their difference along a centreline transect. The trendline indicates that the distortion is approximately $1 / 800$ of the length of the surface. This particular case was different from the rest in that the left camera was adjusted between image acquisitions (to achieve better coverage of the soil surface), leading to a noticeable shift in the field of view. Systematic distortion effects may have been present in all the 
DEMs, but they cancel out for DEM differences if the cameras were stable between image acquisitions.

\section{Comparison with Laser Scanner Measurements}

The dome effect can also be observed in the difference between the respective DEMs derived from photogrammetry and laser scanning for the beforerun soil surface for R1, Scenario D (Fig. 11). The difference map has a mean of $-0.92 \mathrm{~mm}$ and a standard deviation of $3.50 \mathrm{~mm}$. Fig. 12 shows the difference values along a diagonal transect from bottom right to top left. We can infer from the trendline that the distortion in the photogrammetry-derived DEM is approximately 1 in 500 relative to the diagonal of the soil surface. Nevertheless, Fig. 13 shows that the DEM captures essentially the same surface features as that derived from laser scanning, albeit at a lower resolution.

We note that the dome effect in this comparison is in the opposite direction to that shown in Fig. 10. However, Fig. 10 shows the difference between two photogrammetry-derived DEMs, both of which may be slightly concave relative to laser scanner measurements (if they had been obtained). Another possible explanation is, two cameras were used in that case, whereas only one was available in this. A similarly convex DEM distortion was observed by Blaes and Defourny (2008) with their two-camera configuration. We expect that, in general, the direction and magnitude of the dome effect would depend on the photogrammetric configuration, the cameras used, the accuracy of the lens models, etc.

One may legitimately ask if a different self calibration strategy would yield better results. Since the dome effect may be due to the use of inaccurate lens models, we performed the triangulation in LPS with two additional radial distortion parameters $\left(k_{1}, k_{2}\right)$ and used the results to revise the lens model in the 'Digital Camera Frame Editor'. This was done iteratively until the changes in $k_{1}$ and $k_{2}$ were less than $1 \%$ of the previous values.

As might be expected, there was a reduction in the image point RMSE when additional parameters (APs) were included (2.46 microns versus 3.35 microns when no APs were used). However, the DEM generated using this strategy suffered from the same systematic effect (Fig. 12). The mean difference between this DEM and that derived from laser scanning was $0.86 \mathrm{~mm}$, with a standard deviation of $3.34 \mathrm{~mm}$. Thus there seems to be no advantage using this time consuming approach over the simpler one adopted in this study.

The above discussion assumes that the measurements acquired by the laser scanner are accurate, whereas in reality there are errors associated with any technique. Since the soil surface was scanned from two different positions, we may compare the DEMs generated from the two point clouds in the overlapping area. The difference map (Fig. 14) has a mean of $0.92 \mathrm{~mm}$ and a standard deviation of $2.09 \mathrm{~mm}$. A systematic trend can be observed: the upper slope is predominantly negative and the lower slope positive. This may be due to relative positioning errors. As explained in the Methodology, the orientation of the point clouds is subject to errors in locating the targets attached to the sides of the flume. There are also occlusion effects, particularly evident on the upper slope, due to 
large aggregates on the soil surface. The errors associated with laser scanning are clearly not insignificant, although they are within the instrument's specifications. In addition to these quantifiable uncertainties, questions may be asked about the behaviour of a laser beam when it hits a soil aggregate and how this affects the measurement, the accuracy of measuring a rough surface with roughness elements smaller than the laser spot size, etc.

\section{DISCUSSION}

\section{Precision and Accuracy of the Technique}

The analyses in the previous section highlight the main problems with the photogrammetric configuration adopted in this study. In the first place, the weak geometry of the setup meant that the triangulation solutions were sensitive to variations in point measurement and tie point distribution. This had a negative impact on the precision of the DEMs. In practical terms, this affects the reliability of assessments of surface change due to erosion events. On the other hand, the error values plotted in Fig. 7 are probably on the pessimistic side, having been exaggerated by the nearest neighbour interpolation scheme.

The precision of point measurements is dependent on image quality, which could perhaps be improved by using mirror lock-up to reduce camera vibrations during exposure or by using a higher ISO rating to minimise exposure times. Further investigations would have to be done to determine the respective merits of these measures.

The geometric configuration may be improved by fixing additional GCPs outside the flume and out of the plane of the soil surface. This requires that the flume be fixed relative to these external GCPs. As such, it may not be suitable for tilting flumes and where the position of the flume is likely to be disturbed during experimentation. Alternatively, a larger base distance and wider angle of convergence may be adopted (Fraser, 1996). However, given that we are dealing with natural surfaces, a large $B: H$ ratio may adversely affect the distribution and accuracy of the automatically extracted mass points due to poor feature matching. Further research would have to be carried out to identify the optimal angle of convergence for such soil surfaces.

The other issue has to do with dome effects in the DEMs, which could be due to inaccuracies in the radial distortion models. Although convergent imagery can reduce the impact of inaccurate lens models (Wackrow and Chandler, 2008), it is evident, in the earlier study as well as in this, that distortions increase with increasing distance from the centre of convergence. We may also note that the distortions in this study ( 1 in 500 of the largest dimension) are on par with those obtained by Stojic et al. (1998) and Wackrow and Chandler (2008) with normal imagery.

We cannot rule out tangential lens distortions as a contributing factor. Under normal circumstances, with accurately centred and parallel lens components, tangential distortions are an order of magnitude smaller than radial effects and hence negligible (Luhmann et al., 2006). This may not hold with the variable 
zoom lenses used in this study (Wiley and Wong, 1995). On the other hand, previous unpublished work with these lenses has not revealed significant tangential effects. Also, given the weak geometry of the photogrammetric network, we did not feel it was appropriate to include additional tangential distortion parameters during self calibration.

Although errors in the lens models could have contributed to the dome effects, a more significant factor, perhaps, is the variation in lens distortion with object distance. Brown (1971) showed that radial distortion varies with the focused distance (for a fixed object distance) according to the equation

$$
\delta r_{s, s^{\prime}}=\frac{s}{s^{\prime}} \cdot \frac{s^{\prime}-f}{s-f} \delta r_{s^{\prime}}
$$

where $\delta r_{s, s^{\prime}}$ is the distortion at object distance $s^{\prime}$ for a lens focused at object distance $s, \delta r_{s^{\prime}}$ is the corresponding distortion for a lens focused at object distance $s^{\prime}$, and $f$ is the focal length. The same scaling factor applies for decentring distortions (Fryer and Brown, 1986). Thus, for a photographic field with varying object distances, lens distortion effects are overestimated for points in the near field and vice versa.

The image field in this study ranged from 1.9 to $4.8 \mathrm{~m}$, with the plane of best focus at approximately $3 \mathrm{~m}$. For $f=22 \mathrm{~mm}$, the ratio $\delta r_{s, s^{\prime}} / \delta r_{s^{\prime}}$ is $0.996(1.003)$ for points in the near (far) field. Given a calibrated radial distortion of 42 microns at $10 \mathrm{~mm}$ (the size of the sensor is $23.6 \times 15.8 \mathrm{~mm}$ ), deviations from the calibrated values due to varying object distance would be approximately 0.17 microns maximum. Thus it seems that the large image residuals and the dome effects are not largely due to the variation of distortion with object distance. Of course, Equation (3) may not be accurate for the lenses used in our study and, as Fraser and Shortis (1992) and Shortis et al. (1998b) showed, the exact relationship between lens distortion and object distance is rather more complex. In any case, this dependence of distortion on object distance would explain why the dome effect was not eliminated by the inclusion of lens distortion APs in self calibration.

If the measurement of surface change is of paramount importance, then systematic dome effects in the DEMs cancel out and can therefore be ignored, provided that changes are small and camera orientations are fixed. On the other hand, these dome effects have definite implications where the derived elevation data is used for overland flow and sediment transport modelling. Given that the dome effects are due to a complex combination of the factors mentioned above, the problem could be resolved, in the absence of more robust camera models, by applying corrections to the DEMs that are of opposite signs to the systematic distortions. A testfield similar to that used by Rieke-Zapp and Nearing (2005) could be used to determine the corrections that should be applied.

An alternative solution would be to reduce the obliqueness of the imagery and so decrease the object depth. In this case, the number of imaging stations would have to be increased to cover the whole surface area. One possible configuration would be to have two fixed camera stations above the top of the 
flume in additional to those at the end. Besides addressing the distortion issue, this setup would also reduce the number of spurious points near the top of the flume and enhance overall DEM resolution. Ideally, there should be one camera for each imaging station so as to minimise the time required for image acquisition. This would of course increase the complexity and cost of the technique, and the time required for photogrammetric processing.

Notwithstanding the above issues, Figs. 8, 10 and 13 show that the CRDP technique applied in this study can consistently reproduce sub-centimetre features on the soil surface. This suggests that reliable surface roughness indices, which are independent of the larger-scale distortions, can be obtained using this technique. Also, as we demonstrate in the following subsection, DEMs of slopes designed to be replicates can be compared to examine the effect of small topographical variations on the erosion response.

Before- and after-run DEMs can be differenced to quantify volumetric changes due to soil erosion, provided we take into consideration the uncertainties due to the weak geometric configuration. Spatial variations in morphology, which is a function of relative rather than absolute changes in elevation, can also be reliably obtained from the DEMs. They provide pictures of spatial variations in erosivity and/or erodibility that can enhance our understanding of erosion processes. We demonstrate these uses of the photogrammetric output in the following subsections.

\section{Topographical Irregularities}

The contour maps generated in conjunction with DEM extraction can highlight otherwise imperceptible topographical irregularities that may impact soil erosion processes. For instance, the contour map of the soil surface used for R3 in Scenario B (Fig. 15) shows that the slope, while designed to be uniform at $6 \%$, was gentler on the upper reach than on the lower. Also, the contour lines in the 15 $\mathrm{cm}$ exclusion zones on either side of the flume (shaded in the figure) indicate that surface runoff in those regions could have been channelled into the central region. This would explain why, for some of the runs, the measured steady-state discharge exceeded the theoretical maximum (rainfall intensity multiplied by the area of the central region).

Seemingly insignificant topographical differences may also account for differences in the erosion response between replicate runs. Fig. 16 shows the discharges and suspended sediment concentrations (SSC) in runoff from the triplicate runs in Scenario A. The time between the start of rainfall and the collection of the first sample (for measureable discharge) was shorter for R3 than for the earlier two runs. The sediment response in R3 was significantly different, with concentration rising to a peak before falling to approach steady state. In the absence of further information, one may be led to think that the observations in R3 were anomalous. An examination of the slopes (Fig. 17) reveals, however, that there were slight depressions near the end of the slopes used in R1 and R2. This would have resulted in significant ponding at the end of the slopes (which was actually observed), with correspondingly greater surface storage. This would explain the longer times to runoff for R1 and R2. It would also explain the absence 
of an initial rise in SSC (as was observed for all other runs in Scenarios A, B, C and $\mathrm{D}$ ): the delay in time-to-runoff meant that surface shielding and sealing had already developed to some extent by the time the first samples were collected. The additional information derived from photogrammetry suggests, contrary to initial speculations, that the R3 data may be more representative of the response of a uniform $3 \%$ slope than the other two datasets.

\section{Surface Elevation Changes}

We derived surface elevation changes due to erosion events by subtracting before-run DEMs from corresponding after-run models. Fig. 18 plots the soil losses derived from these difference DEMs (based on an approximate soil bulk density of $1.3 \mathrm{~kg} / \mathrm{m}^{3}$ ) against the measured values (based on the collected runoff). The error bars (derived from the mean errors shown in Fig. 7) indicate the range of values that would be obtained if different combinations of before- and after-run DEMs were used. We do not have error estimates for Scenario D as we did not have multiple images of the same surface to work with. It is clear from Fig. 18 that changes in surface elevation bear little relation to soil losses, at least in surface runoff, even if DEM uncertainties were taken into account. This points to the significance of processes that alter soil bulk density (compaction due to rainfall, ingress of fine sediment into the matrix, etc.) in relation to surface morphology, and is further evidence that soil losses cannot easily be predicted from surface elevation changes alone (Rieke-Zapp and Nearing, 2005).

Notwithstanding the above limitation, spatial variability maps of surface elevation change can offer insights on soil erosion processes. As Fig. 19 shows, there is significant correlation between rainfall variability and spatial variations in surface elevation change, in that surface elevation dropped more significantly under high-intensity rainfall and vice versa. Craters created by drips from the rainfall simulator nozzles (when switched off) are also visible in the surface change map. This demonstrates the potential of the CRDP technique for investigations into the influence of rainfall variability on slope morphology.

CRDP can also be used to study topographical controls on soil erosion processes. Fig. 20 shows that significant sediment deposition occurred at the confluence of runoff pathways and in depressions, which is consistent with the physics of erosion and sediment transport processes. This highlights the value of high-resolution CRDP in detecting the subtle topographical variations that impact upon erosion processes and the resulting landform evolution.

In Scenario E, the clear inflow was gradually increased until rills started to form (at discharges of approximately $0.5 \mathrm{l} / \mathrm{s}$ ). The initial unconcentrated flow produced diffused erosion and deposition patterns respectively on the upper (steeper) and lower (gentler) reaches of the slopes (Fig. 21), the deposition areas indicating where the overland flow was deepest due to the heterogeneity of the slopes in the transverse direction. Rills began to appear with increasing inflow, resulting eventually in the flow being wholly concentrated within the rills. Nevertheless, the change in slope dampened flow energy sufficiently in R1 resulting in a depositional fan on the lower reach. Further studies, which will rely 
heavily on the CRDP technique, may be conducted on the relationship between rill network topology and initial perturbations in surface topography.

\section{CONCLUSIONS}

We have described in this paper an application of CRDP in soil erosion studies. The requirements and constraints of the project led us to adopt an unconventional and perhaps overly ambitious setup, namely, an oblique convergent configuration that facilitated complete stereo coverage of the soil surface from just two fixed camera positions. We have also discussed the use of LPS 9.0 in this study, and the appropriate triangulation, tie point generation and DEM extraction parameters for our particular setup.

The effects of varying tie point distributions and point measurement errors on the triangulation solutions and the resulting DEMs were investigated. By comparing DEMs of the same surface extracted from different image pairs, we found that the precision was, on average, $2.59 \mathrm{~mm}$ (one standard deviation), although this is a pessimistic estimate affected by the interpolation scheme.

The accuracy of the technique was investigated by comparison against data acquired by a terrestrial laser scanner. This revealed that the photogrammetryderived DEM suffered from a dome effect that can be attributed to a combination of inaccuracies in the lens models and a large object depth due to the oblique imagery.

Notwithstanding the above issues, this study has shown that CRDP can be usefully applied in soil erosion studies. In particular, it allows us to study the influence of small-scale topography on runoff and erosion responses, and the resulting morphological evolution. Slight topographical variations between replicates may explain the variability of experimental results observed in this and many previous soil erosion studies (e.g., Bryan and Luk, 1981; Wendt et al., 1986; Nearing et al., 1999). The topographical information can also be used as input in a physics-based soil erosion model and for validating model output.

The advantages of CRDP over other surface measurement techniques such as laser scanning are the rapid acquisition of data (that could be used for spectral as well as morphological analyses), and the relative simplicity and cost effectiveness of the equipment. The oblique convergent configuration facilitates instantaneous capture of the whole surface from unintrusive camera positions, thereby reducing the time required both to acquire and to process the data.

Further investigations may be conducted to address outstanding issues with the technique. Possible measures to improve precision and accuracy may include strengthening the geometric configuration with additional GCPs and a wider angle of convergence, increasing the number of camera stations so as to reduce the object depth, using fixed focus lenses to minimise uncertainties in lens modelling, and/or determining the corrections needed to compensate for dome effects in the DEMs. 


\section{ACKNOWLEDGEMENTS}

This paper is an extended version of one presented at the RSPSoc Annual Conference 2009 and published in the Conference Proceedings (Heng, B. C. P., Chandler, J. H., and Armstrong, A., 2009. Applying Close Range Digital Photogrammetry in Soil Erosion Studies. Proceedings of RSPSoc 2009 Annual Conference, RSPSoc, Nottingham. 776 pages: 197-206). The work was funded by the Natural Environment Research Council (grant number NE/E007015/1). The authors acknowledge the helpful comments by Rene Wackrow on an early draft of this paper.

\section{REFERENCES}

Abd Elbasit, M. A. M., Anyoji, H., Yasuda, H., And Yamamoto, S., 2009. Potential of low cost close-range photogrammetry system in soil microtopography quantification. Hydrological Processes, 23(10):1408-1417.

Aguilar, M. A., Aguilar, F. J., AND Negreiros, J., 2009. Off-the-shelf laser scanning and closerange digital photogrammetry for measuring agricultural soils microrelief. Biosystems Engineering, 103(4):504-517.

Armstrong, A., Quinton, J. N., Heng, B. C. P., And Chandler, J. H., in review. Dominant controls over interrill soil erosion at low slopes. Earth Surface Processes and Landforms.

BlaEs, X. AND DEFourny, P., 2008. Characterizing bidimensional roughness of agricultural soil surfaces for SAR modeling. IEEE Transactions on Geoscience and Remote Sensing, 46(12):40504061.

BRown, D. C., 1971. Close-range camera calibration. Photogrammetric Engineering, 37(8):855-866.

BRYAN, R. AND LUK, S., 1981. Laboratory experiments on the variation of soil erosion under simulated rainfall. Geoderma, 26(4):245-265.

ChANDler, J. H., FrYer, J. G., AND JACK, A., 2005. Metric capabilities of low-cost digital cameras for close range surface measurement. The Photogrammetric Record, 20(109):12-26.

FrASER, C. S., 1996. Network design. In Close Range Photogrammetry and Machine Vision (Ed. K. B. Atkinson). Whittles Publishing, Caithness, Scotland. 384 pages: 256-281.

Fraser, C. S. AND SHORTIS, M. R., 1992. Variation of distortion within the photographic field. Photogrammetric Engineering and Remote Sensing, 58(6):851-855.

FRYER, J. G. AND BROWN, D. C., 1986. Lens distortion for close-range photogrammetry. Photogrammetric Engineering and Remote Sensing, 52(1):51-58.

Helming, K., Roth, C., Wolf, R., AND Diestel, H., 1993. Characterization of rainfall-microrelief interactions with runoff using parameters derived from digital elevation models (DEMs). Soil Technology, 6(3):273-286.

JESTER, W. AND KLIK, A., 2005. Soil surface roughness measurement-methods, applicability, and surface representation. CATENA, 64(2-3):174-192.

Kraus, K., 1993. Photogrammetry, 4th Ed. Vol. 1. Ferd. Dümmers Verlag, Bonn, Germany. 402 pages.

Lascelles, B., Favis-Mortlock, D., Parsons, T., And BoArdman, J., 2002. Automated digital photogrammetry: A valuable tool for small-scale geomorphological research for the nonphotogrammetrist? Transactions in GIS, 6(1):5-15.

LeICA GeOSYSTEMS, 2005. Leica Photogrammetry Suite Project Manager User's Guide. Leica Geosystems Geospatial Imaging, LLC, Norcross, Georgia, USA. 378 pages.

LeICA Geosystems, 2007. Leica ScanStation 2 Data Sheet. Leica Geosystems AG, Heerbrugg, Switzerland. 2 pages.

Leica Geosystems, 2008. Leica Cyclone Version 6.0. Leica Geosystems HDS LLC, San Ramon, California, USA. On-line help.

Luhmann, T., Robson, S., Kyle, S., And Harley, I., 2006. Close Range Photogrammetry: Principles, Methods and Applications. Whittles Publishing, Caithness, Scotland. 528 pages.

MARTIN, L., 1980. An assessment of soil roughness parameters using steoreophotography. In Assessment of Erosion (Eds. M. de Boodt and D. Gabriels). John Wiley \& Sons, Chichester. 563 pages: 237-248. 
MERel, A. P. AND FARRES, P. J., 1998. The monitoring of soil surface development using analytical photogrammetry. The Photogrammetric Record, 16(92):331-345.

MikHAIL, E. M., BeTHEL, J. S., AND MCGLONE, J. C., 2001. Introduction to Modern Photogrammetry. John Wiley \& Sons, Inc., New York. 496 pages.

Nearing, M. A., Govers, G., AND NoRTON, 1999. Variability in soil erosion data from replicated plots. Soil Science Society of America Journal, 63(6):1829-1835.

RIEKE-ZAPP, D. H. AND NEARING, M. A., 2005. Digital close range photogrammetry for measurement of soil erosion. The Photogrammetric Record, 20(109):69-87.

Rieke-Zapp, D., Tecklenburg, W., Peipe, J., Hastedt, H., And Haig, C., 2009. Evaluation of the geometric stability and the accuracy potential of digital cameras - comparing mechanical stabilisation versus parameterisation. ISPRS Journal of Photogrammetry and Remote Sensing, 64(3):248-258.

Shortis, M. R., Robson, S., AND Beyer, H. A., 1998a. Principal point behaviour and calibration parameter models for Kodak DCS cameras. The Photogrammetric Record, 16(92):165-186.

SHORTIS, M. R., RoBSON, S., AND BEYER, H. A., 1998b. Extended lens model calibration of digital still cameras. International Archives Photogrammetry and Remote Sensing, 32(5):159-164.

Stojic, M., ChAndler, J., AshmoRe, P., AND LUCE, J., 1998. The assessment of sediment transport rates by automated digital photogrammetry. Photogrammetric Engineering and Remote Sensing, 64(5):387-395.

TACONET, O. AND CIARLETTI, V., 2007. Estimating soil roughness indices on a ridge-and-furrow surface using stereo photogrammetry. Soil and Tillage Research, 93(1):64-76.

Takken, I., Jetten, V., Govers, G., Nachtergaele, J., And Steegen, A., 2001. The effect of tillage-induced roughness on runoff and erosion patterns. Geomorphology, 37(1-2):1-14.

Toy, T. J., Foster, G. R., and Renard, K. G., 2002. Soil Erosion: Processes, Prediction, Measurement, and Control. John Wiley \& Sons, Inc., New York. 338 pages.

WACKROW, R. AND CHANDLER, J. H., 2008. A convergent image configuration for DEM extraction that minimises the systematic effects caused by an inaccurate lens model. The Photogrammetric Record, 23(121):6-18.

Wendt, R. C., AlberTs, E. E., And HJelmfelt, A. T., 1986. Variability of runoff and soil loss from fallow experimental plots. Soil Science Society of America Journal, 50(3):730-736.

WILEY, A. G. AND WONG, K. W., 1995. Geometric calibration of zoom lenses for computer vision metrology. Photogrammetric Engineering and Remote Sensing, 61(1):69-74.

ZRibi, M., Ciarletti, V., TACONet, O., PAille, J., AND Boissard, P., 2000. Characterisation of the soil structure and microwave backscattering based on numerical three-dimensional surface representation analysis with a fractional Brownian model. Remote Sensing of Environment, 72(2):159-169. 
NAME. Title of paper

Fig. 1. Schematic diagram showing the experimental and photogrammetric setup. Laser scanning was carried out from two positions in order to cover the whole surface.

Fig. 2. Image of the flume acquired by the left camera, showing the GCP targets fixed to the sides of the flume.

Fig. 3. Automatically generated tie points on the soil surface.

Fig. 4. Merged point cloud of the test flume acquired by laser scanning.

Fig. 5. Typical image point residuals (magnified 30 times), showing systematic effects. Tie points denoted by black squares, GCPs by red triangles, and check points by blue circles. Left: All control and tie points active. Right: Subset of control and tie points within the top half of the slope active.

Fig. 6. Mass point distribution and corresponding raster DEM extracted from images acquired before R1 of Scenario B using the default search window of $21 \times 3$ pixels (left), and using a larger search window of $21 \times 9$ pixels (right).

Fig. 7. Mean errors and standard deviations derived by differencing DEMs of the same surface. On the $x$ axis, capital letters $\mathrm{A}, \mathrm{B}, \mathrm{C}$ and $\mathrm{E}$ denote the respective scenarios, R\# denotes replicate number, bf and af respectively denote use of images acquired before and after the erosion events. Pixels in the difference DEMs with absolute values greater than $25 \mathrm{~mm}$, typically accounting for $1 \%$ of the total surface area, were excluded from the analysis.

Fig. 8. Elevation values along the transect $Y=103.200 \mathrm{~m}$ for two DEMs of the same surface (following R1 of Scenario E), taking into account random errors in the measurement of the GCPs. The inset graph shows clearly that the two DEMs are offset by approximately $10 \mathrm{~mm}$.

Fig. 9. Difference map derived from DEMs of the soil surface before R2 of Scenario B, showing the systematic dome effect. Grey pixels denote values outside the range [ $-25 \mathrm{~mm}, 25 \mathrm{~mm}]$.

Fig. 10. Top: Elevation values along the centreline of the DEMs used to derive Fig. 9. Bottom: Difference between elevation values, with polynomial trendline (of order 2) showing dome effect.

Fig. 11. Difference between the photogrammetry-derived DEM (self calibration without APs) and that derived from laser scanning for the soil surface before R1 of Scenario D.

Fig. 12. Difference values (red crosses) along a diagonal transect from bottom left to top right of Fig. 11, with 3rd-order polynomial trendline (red continuous line) showing the distortion. For comparison, we have also plotted (blue circles, dashed line) the difference between a DEM derived using a revised lens model (see text) and the laser scanner data.

Fig. 13. Visual comparison of the photogrammetry-derived DEM (top) and that derived from laser scanning (bottom).

Fig. 14. Difference map (of the overlapping area) based on DEMs generated from different point clouds acquired by the laser scanner. Laser scanner's restricted field of view (vertical) resulted in a circular void in one of the DEMs. 
Fig. 15. Contour map (10 mm intervals) of the soil surface before R3 of Scenario B. Shaded regions demarcate designated exclusion zones. Direction of flow is from left to right.

Fig. 16. Discharge and suspended sediment concentration (SSC) measurements for Scenario A, with triplicate runs R1, R2 and R3. The $x$ axis shows time since the start of rainfall.

Fig. 17. Contour maps ( $10 \mathrm{~mm}$ intervals) of the soil surfaces before R1 (left), R2 (centre) and R3 (right) of Scenario A. Direction of flow is from top to bottom.

Fig. 18. Comparing calculated soil losses (based volumetric differences between the before- and after-run DEMs) against measured soil losses for Scenarios A through E. Error bars based on DEM uncertainties shown in Fig. 7.

Fig. 19. Left: Rainfall variability over soil surface, averaged between measurements taken before and after R1 of Scenario C. Border regions were not monitored. Right: Surface elevation change map for R1 of Scenario C. The boundaries of the flume are demarcated by the borders around the two maps.

Fig. 20. Slope contours (based on before-run DEMs) superimposed on surface elevation change maps for A/R1 (left) and C/R3 (right) highlight topographical controls on soil erosion. Contour lines are at $10 \mathrm{~mm}$ intervals; pixel colours are as defined in Fig. 19.

Fig. 21. Surface elevation changes due to the runoff-driven erosion events in Scenario E. 

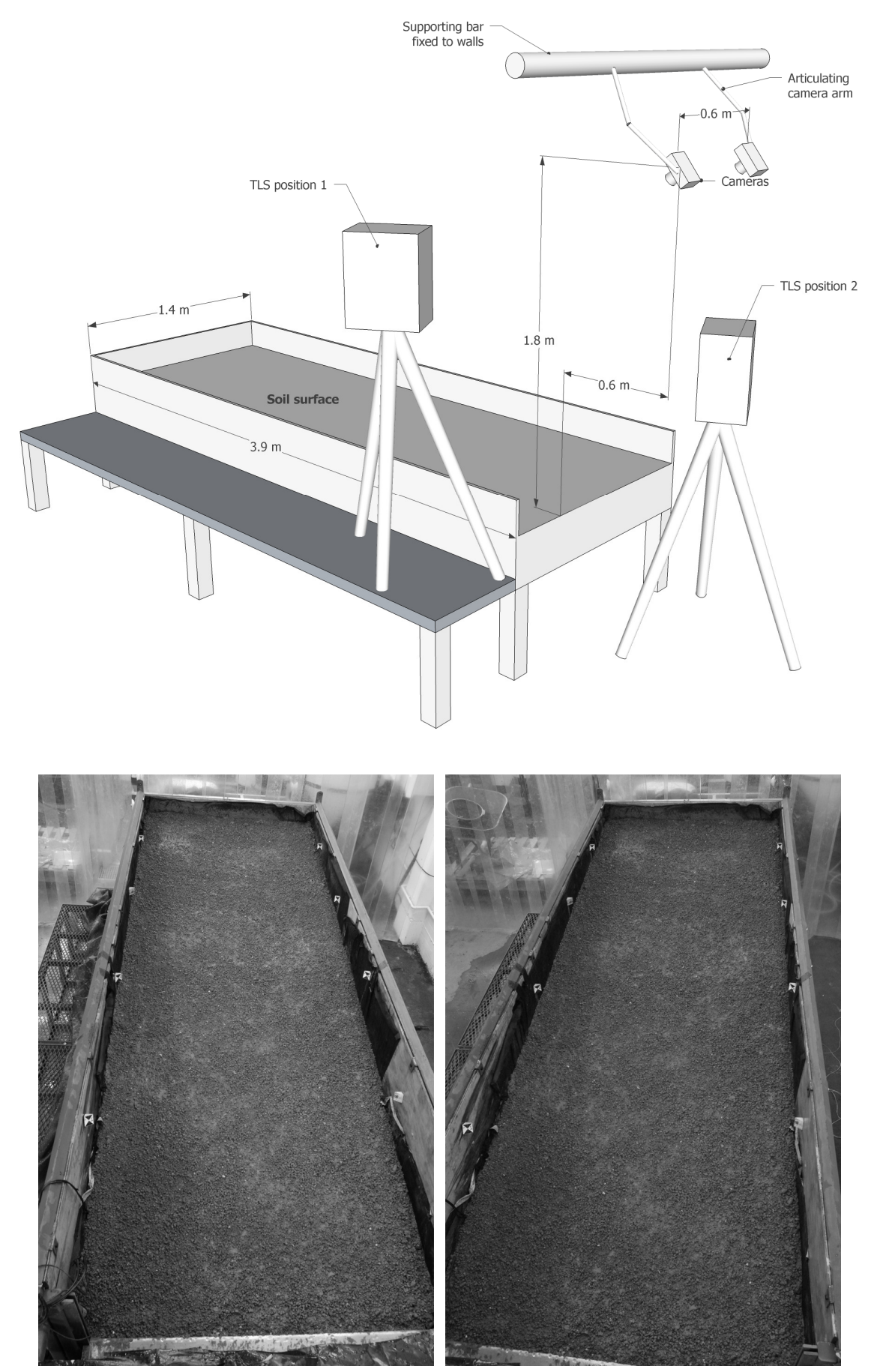
NAME. Title of paper
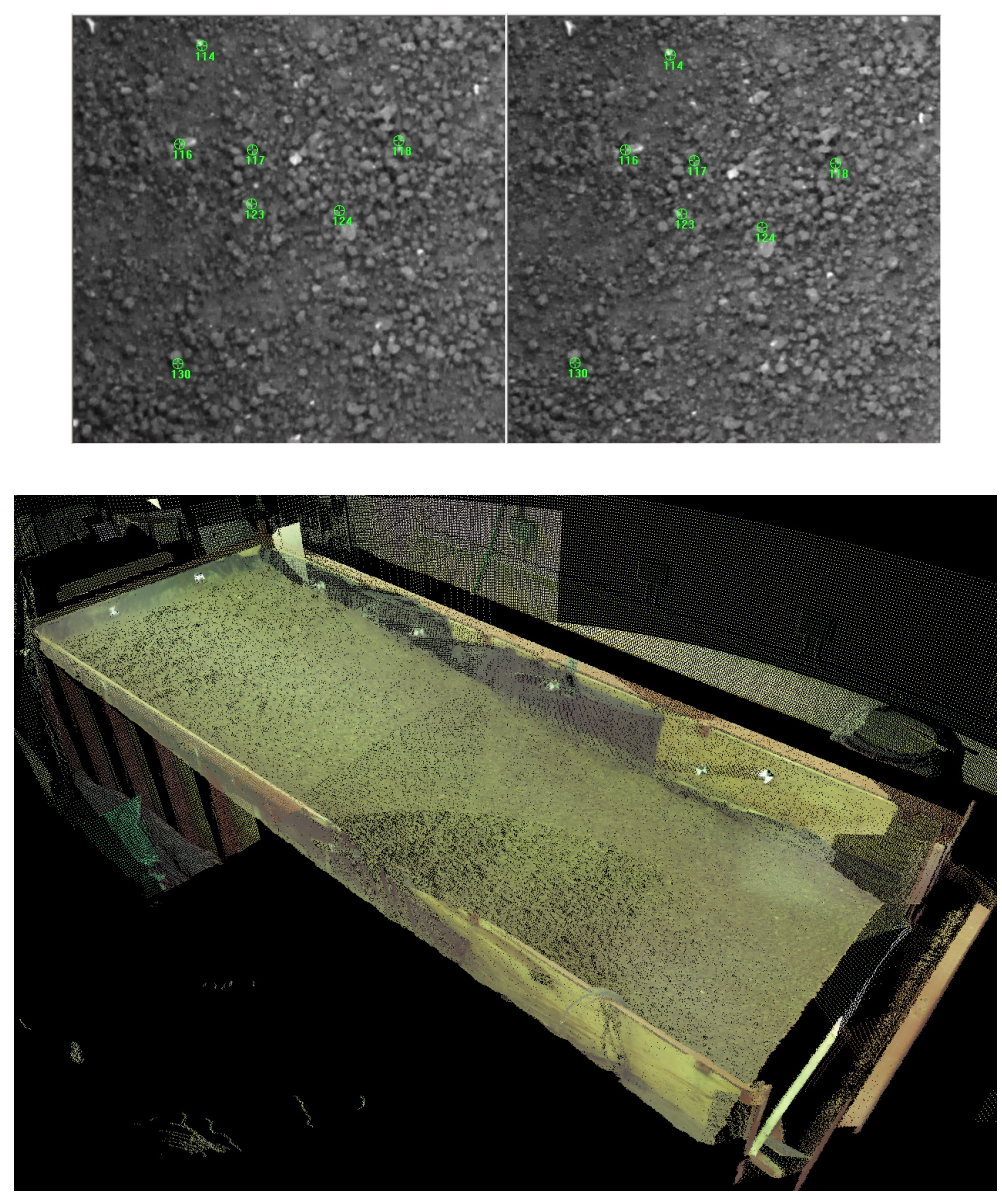

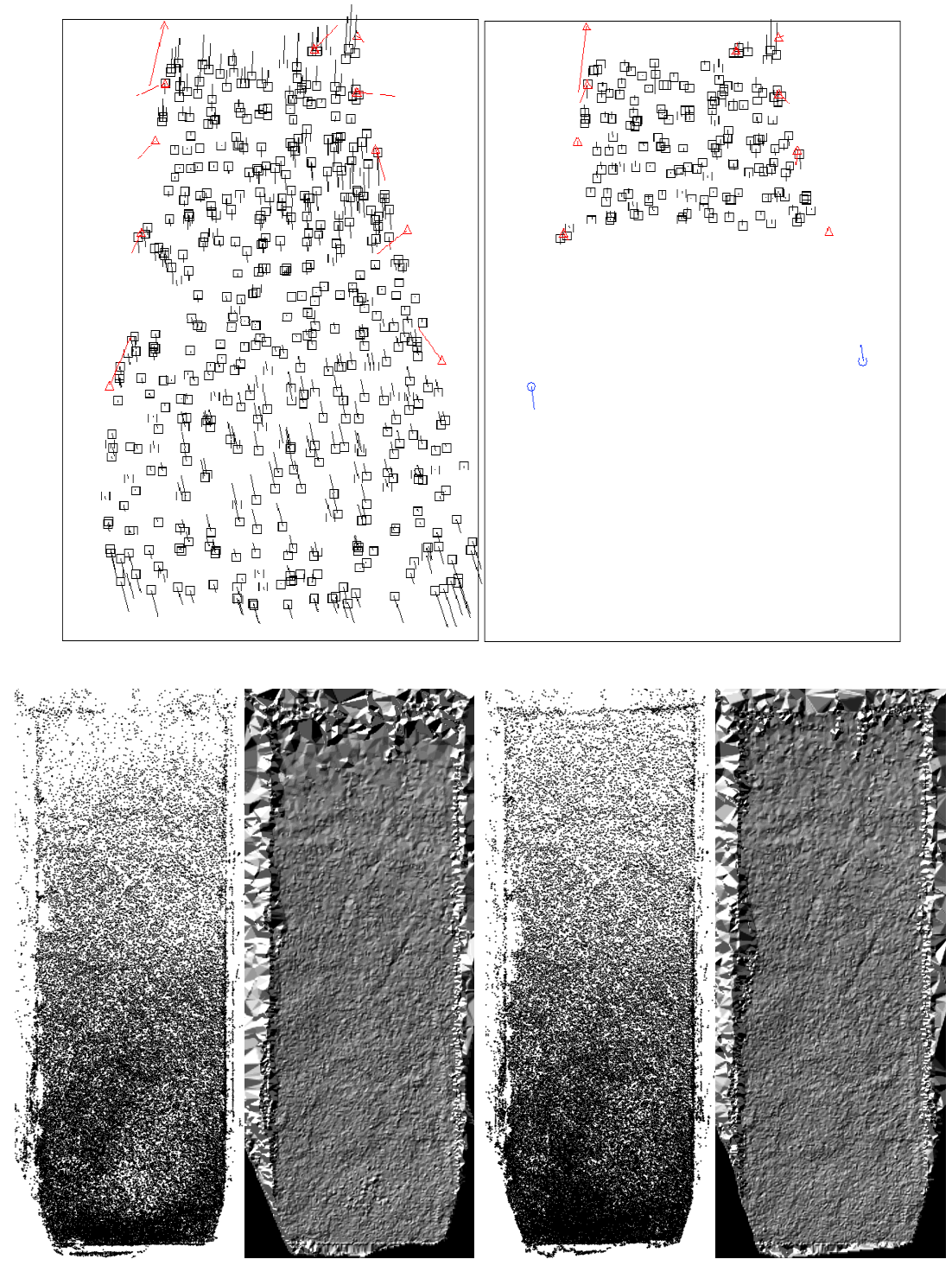

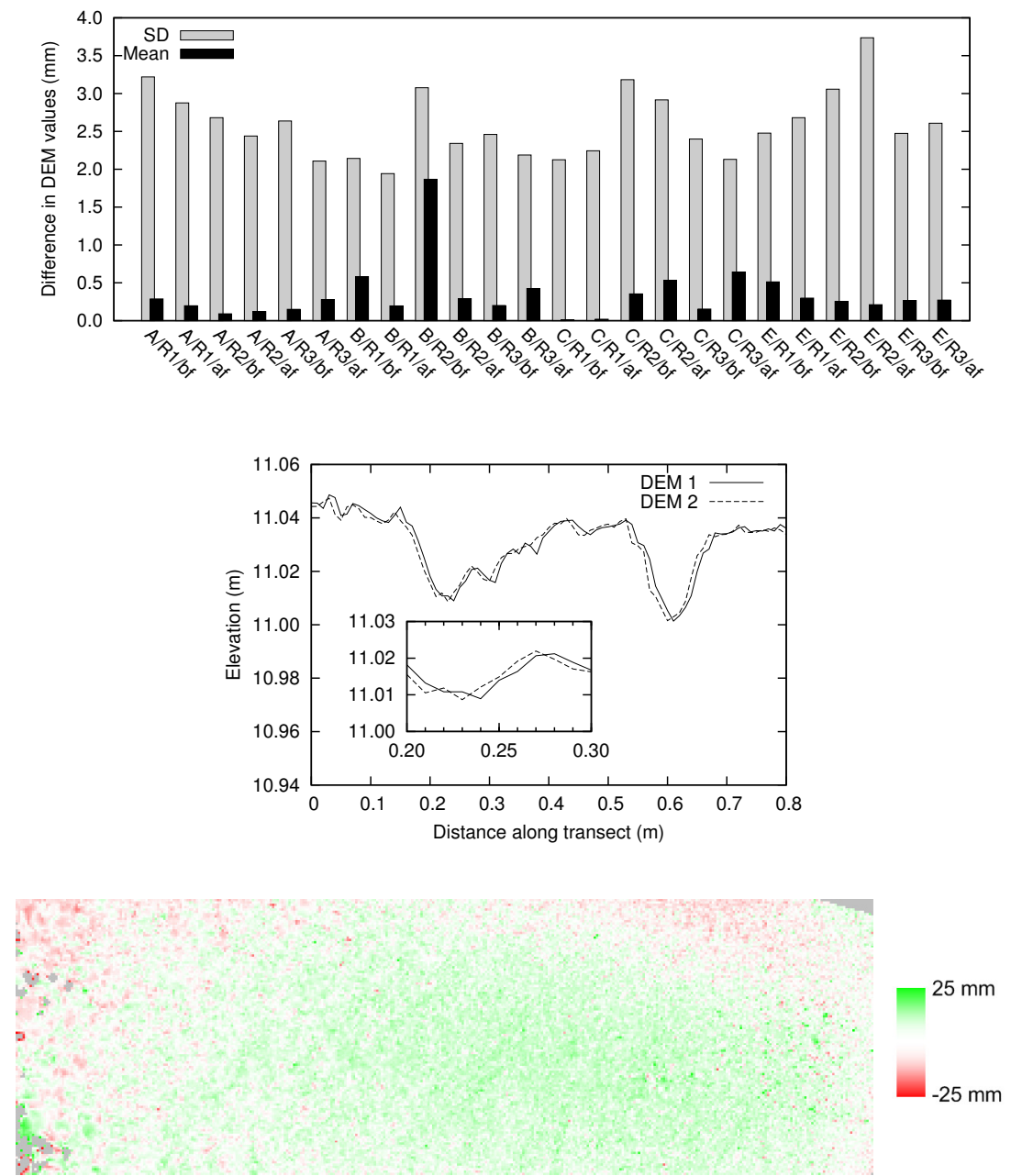
NAME. Title of paper
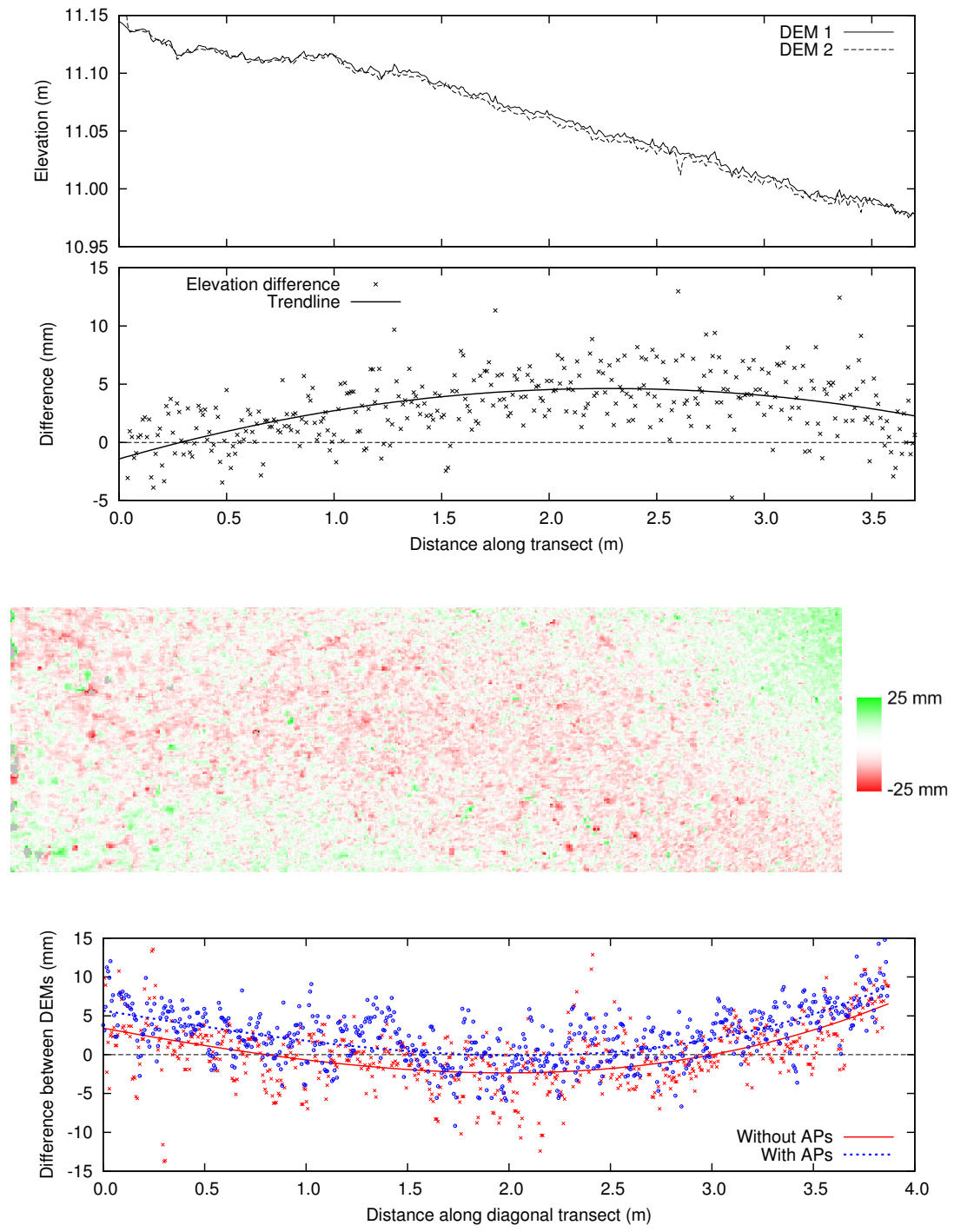

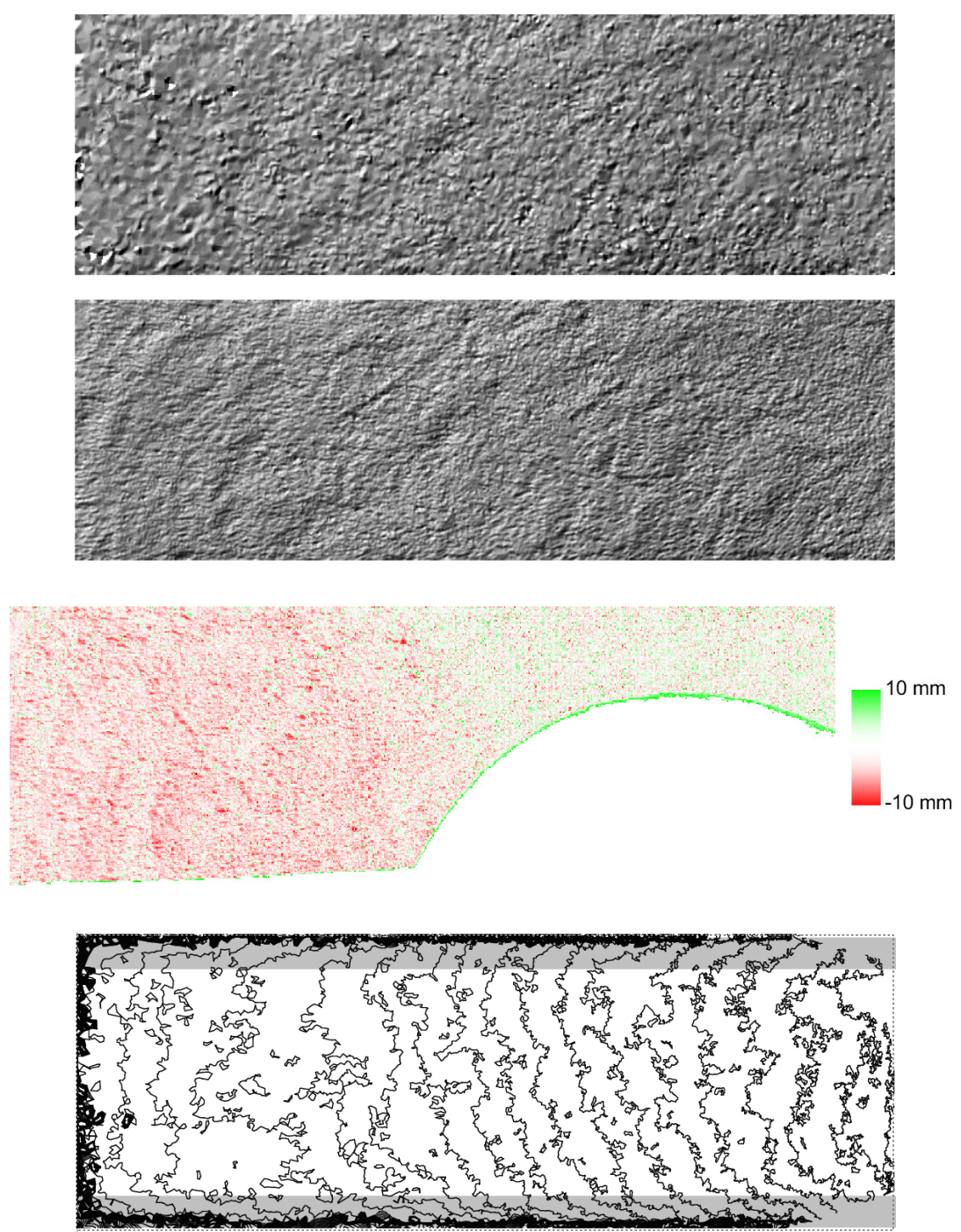
NAME. Title of paper
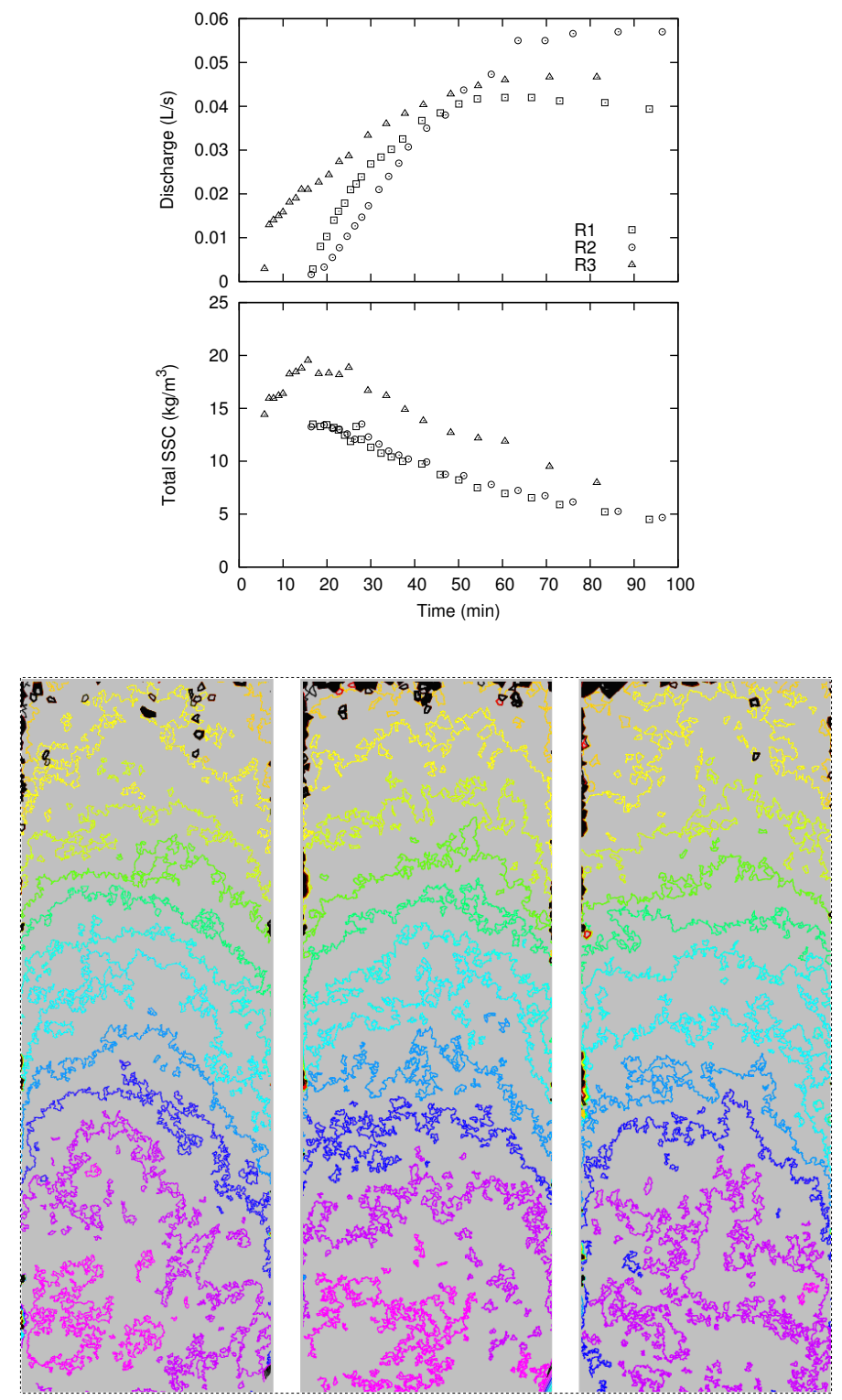
NAME. Title of paper
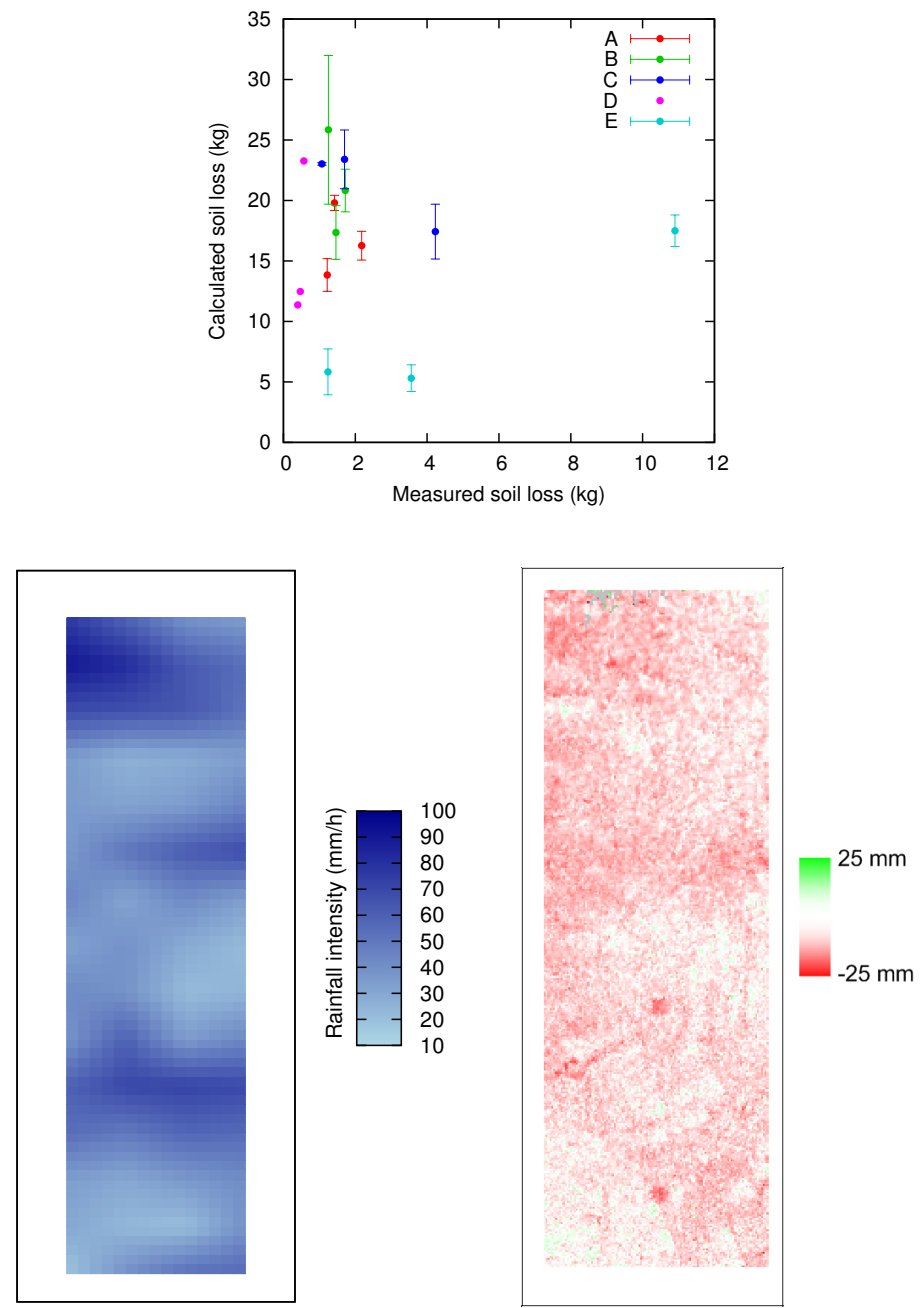
NAME. Title of paper
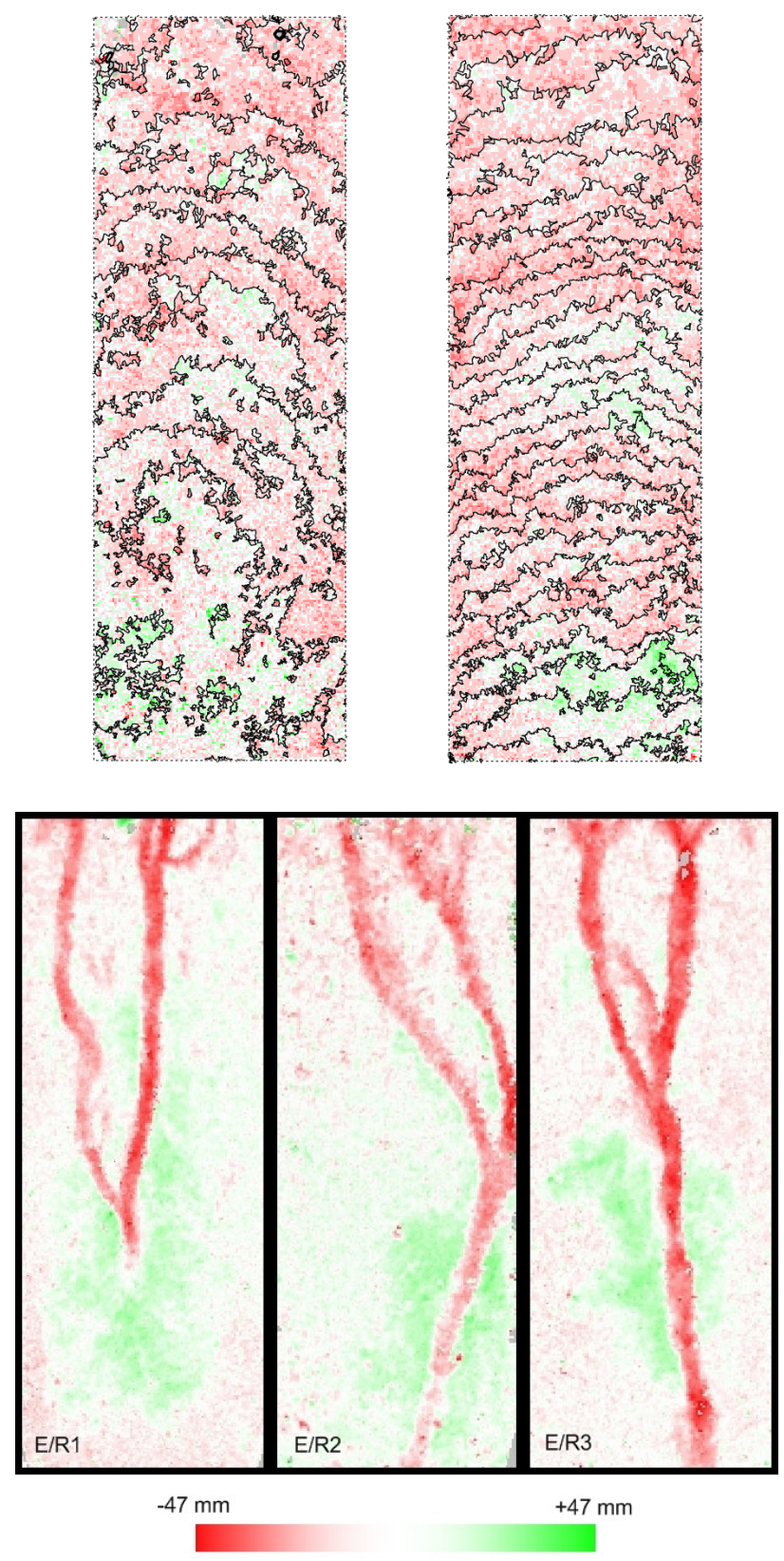